\title{
Effects of CYP2D6 genetic polymorphisms on the efficacy and safety of fluvoxamine in patients with depressive disorder and comorbid alcohol use disorder
}

This article was published in the following Dove Press journal:

Pharmacogenomics and Personalized Medicine

Mikhail Sergeevich

Zastrozhin ${ }^{1,2}$

Elena Anatolievna Grishina ${ }^{3}$

Nataliya Petrovna

Denisenko ${ }^{3}$

Valentin Yurievich Skryabin ${ }^{2}$

Dmitry Dmitrievich

Markov $^{3}$

Ludmila Mikhailovna

Savchenko'

Evgeny Alekseevich Bryun ${ }^{1,2}$

Dmitry Alekseevich Sychev ${ }^{4}$

'Department of Addictology, Russian Medical Academy of Continuous Professional Education of the Ministry of Health of the Russian Federation, Moscow, Russia; ${ }^{2}$ Department of Addictology, Moscow Research and Practical Center on Addictions, Moscow, Russia; ${ }^{3}$ Research Centre, Russian Medical Academy of Continuous Professional Education of the Ministry of Health of the Russian Federation, Research Centre, Moscow, Russia; ${ }^{4}$ Department of Clinical Pharmacology and Therapy, Russian Medical Academy of Continuous Professional Education of the Ministry of Health of the Russian Federation, Moscow, Russia

Correspondence: Mikhail Sergeevich Zastrozhin

37/I Lyublinskaya street, Moscow,

Russia, 109390

Tel +79 686420092

Email rudnmed@yandex.ru
Background: Fluvoxamine therapy is used for treatment of patients with depressive disorder, but it is often ineffective, and some patients suffer from dose-dependent undesirable side effects such as vertigo, headache, indigestion, xerostomia, increased anxiety, etc. CYP2D6 is involved in the biotransformation of fluvoxamine. Meanwhile, the genes encoding these isoenzymes have a high level of polymorphism, which may affect the protein synthesis.

Objective: The primary objective of our study was to investigate the effects of CYP2D6 genetic polymorphisms on the efficacy and safety of fluvoxamine in patients with depressive disorder and comorbid alcohol use disorder, in order to develop the algorithms of optimization of fluvoxamine therapy for reducing the risk of dose-dependent undesirable side effects and pharmacoresistance. Methods: The study involved 45 male patients (average age: $36.44 \pm 9.96$ years) with depressive disorder and comorbid alcohol use disorder. A series of psychometric scales was used in the research. Genotyping of CYP2D6 $(1846 \mathrm{G}>\mathrm{A})$ was performed using real-time polymerase chain reaction.

Results: According to results of Mann-Whitney $U$-test, statistically significant differences between the efficacy and safety of fluvoxamine were obtained on 9th and 16th days of therapy in patients with $G G$ and $G A$ genotypes (The Hamilton Rating Scale for Depression: 10.0 [10.0; $23.0]$ vs $25.0[24.0 ; 16.0](P<0.001)$ on the 9 th day and $4.0[2.0 ; 5.0]$ vs $6.0[6.0 ; 7.0]$ on the 16th day; The UKU Side Effect Rating Scale: $6.0[4.0 ; 6.0]$ vs $9.0[9.0 ; 10.0](P<0.001)$ on the 9 th day and $5.0[1.0 ; 9.0]$ vs $19.0[18.0 ; 22.0]$ on the 16 th day).

Conclusion: This study demonstrated the lower efficacy and safety of fluvoxamine in patients with depressive disorder and comorbid alcohol use disorders with $G A$ genotype in CYP2D6 $1846 G>A$ polymorphic marker.

Keywords: pharmacogenetics, SSRIs, fluvoxamine, biotransformation, personalized medicine, CYP2D6, depressive disorders, alcohol addiction

\section{Introduction}

It is known that substance dependence is often comorbid with other mental disorders, ${ }^{16,20}$ worsening the prognosis of the course and outcome of both diseases. ${ }^{24}$ The most common comorbid diagnoses in patients with alcohol addiction are affective disorders and depressive disorders. ${ }^{2}$ Treating these patients is a challenge, because one disorder worsens the course of another one.

A list of antidepressants preferred for alcohol addiction treatment includes mianserin, fluoxetine, fluvoxamine, mirtazapine, and sertraline. In contrast to monoamine 
oxidase inhibitors (MAOIs) and tricyclic antidepressants, which enhance the activity of several neuromediators and thereby possess various pharmacological properties (including undesirable ones), the enumerated medications selectively inhibit serotonin reuptake and selectively enhance the activity of this mediator only. ${ }^{10}$

To date, it is proven that CYP2D6 is the primary enzyme responsible for the biotransformation of psychotropic medications. ${ }^{1,12}$ This isoenzyme is encoded by the gene, which evidences a high level of polymorphism. ${ }^{18}$ It allows distinguishing three main groups of allele variants depending on their possible effects on CYP2D6 isoenzyme activity: functional (extensive metabolizers), low-functional (intermediate metabolizers), and nonfunctional (poor metabolizers). In addition, a group of ultra-rapid metabolizers is identified. These individuals carry more than two copies of functional alleles, causing an increased amount of enzyme to be expressed and resulting in the enhanced biotransformation and elimination rates of drug substrates. The most common allele variants associated with poor metabolizer phenotype are $C Y P 2 D 6^{*} 3, C Y P 2 D 6^{*} 4, C Y P 2 D 6^{*} 5$, and $C Y P 2 D 6^{*} 6$. An increased metabolic rate is typical for individuals having duplication and multiplication of the wild-type allele variants, $\left(C Y P 2 D 6^{*} 1\right) x N$ and $\left(C Y P 2 D 6^{*} 2\right) x N$. There is evidence for a significant role of $C Y P 2 D 6$ genotype in the individual response to antidepressants venlafaxine, ${ }^{5,6,13,14}$ fluoxetine, , $^{3,18,22}$ paroxetine, ${ }^{3,17,21}$ and nortriptyline..$^{4,11}$

Fluvoxamine is metabolized by CYP2D6 and CYP1A2 isoenzymes. It has no pharmacologically active metabolites. ${ }^{9}$ Fluvoxamine is also a strong inhibitor of $C Y P 1 A 2, C Y P 2 C 19$, $C Y P 3 A 4$, and $C Y P 2 D 6,{ }^{9}$ which should be considered when prescribing the drug substrates for the listed isoenzymes, including fluvoxamine itself. ${ }^{9}$ Studies focused on the effect of CYP2D6 genetic polymorphisms on fluvoxamine clearance showed contradictory results. Probably these contradictions can be correlated with nonlinear pharmacokinetics induced by phenoconversion. Two studies performed in patients of European and Asian origin suffering from depressive disorder and taking fluvoxamine at doses from 50 to $200 \mathrm{mg} / \mathrm{d}$ revealed that individuals with different genotypes of CYP2D6 polymorphic markers have different fluvoxamine concentration levels. ${ }^{7,23}$ Meanwhile, a study conducted by Ohara et $\mathrm{al}^{15}$ among 46 Japanese patients showed no effect of CYP $2 D 6^{*} 10$ genetic polymorphism on fluvoxamine equilibrium plasma concentration level. The effect of CYP2D6 genotype reduces with the increase of drug dose. The authors correlate it with the inhibitory effect of fluvoxamine on CYP2D6. Based on the data acquired for European and Asian populations, it was proposed that a differentiated approach to the dose titration of fluvoxamine in patients with different metabolic rates was required. For poor metabolizers, it is recommended to reduce the medication dose by $\sim 70 \%$, whereas for ultra-rapid metabolizers it is possible to titrate the dose, if necessary, up to $150 \%$, controlling the fluvoxamine plasma concentration level with therapeutic drug monitoring. ${ }^{19}$

Currently, there is no data on correlation between the CYP2D6 genetic polymorphisms and efficacy and safety of fluvoxamine among Russian patients. Equally important was to conduct this study among the patients with alcohol use disorder as the majority of these individuals, to varying degrees, have liver disorders affecting the biotransformation of xenobiotics. The objective of our study was to investigate the effect of CYP2D6 genetic polymorphisms on the efficacy and safety of fluvoxamine in the Russian population.

\section{Materials and methods}

The study included 45 male patients (average age $36.44 \pm 9.96$ years) with depressive disorder and comorbid alcohol use disorder who underwent inpatient treatment in Moscow Research and Practical Centre on Addictions of the Moscow Department of Healthcare. For the therapy of depressive disorder, patients received fluvoxamine in tablets (Fevarin $^{\circledR}$, Abbott Laboratories, Lake Bluff, IL, USA) at a median dose of 100 [interquartile range: $50 ; 150$ ] mg/d from day 5 to 21 of the inpatient treatment course. The study subjects were recruited consecutively from October 2016 to June 2017, using inclusion and exclusion criteria. The inclusion criterion was 16-day fluvoxamine therapy. Exclusion criteria were the presence of any other psychotropic medications in the treatment regimen except fluvoxamine (with the exception of Phenazepam ${ }^{\circledR}$, Cayman Chemical, Ann Arbor, MI, USA) (bromdihydrochlorphenylbenzodiazepine) administered during the treatment of the alcohol withdrawal syndrome, creatinine clearance values $<50 \mathrm{~mL} / \mathrm{min}$, creatinine concentration in plasma $\geq 1.5 \mathrm{mg} / \mathrm{dL}$ (133 mmol/L), body weight $<60 \mathrm{~kg}$ or $>100 \mathrm{~kg}$, age of 75 years or more, and presence of any contraindications for fluvoxamine use.

The study was approved by the local ethics committee of the Russian Medical Academy of Continuous Professional Education of the Ministry of Health of the Russian Federation (No. 6, September 27th, 2016), and all patients provided written informed consent.

Venous blood samples collected in vacuum tubes, VACUETTE $^{\circledR}$ (Greiner Bio-One, Kremsmünster, Austria) on the 21 st day of the fluvoxamine therapy were used for genotyping. Real-time polymerase chain reaction was performed 
using DNA amplifiers Dtlite of DNA Technology (Moscow, Russia) and CFX96 Touch Real Time System with CFX Manager software of Bio-Rad Laboratories Inc. (Hercules, CA, USA) and sets "SNP-screen" of Syntol (Moscow, Russia). SNP-screen were used to determine single-nucleotide polymorphisms (SNPs) $1846 G>A$ of the gene $C Y P 2 D 6$ (rs3892097, CYP2D6*4). In every "SNP-screen" set, two allele-specific hybridizations were used, which allowed the determination of two alleles of the studied polymorphism separately on two fluorescence channels.

To evaluate the fluvoxamine efficacy, several international psychometric scales were used: The Scale of Pathological Addiction, Penn Alcohol Craving Scale, Visual Analog Scale, Clinical Global Impression, Hospital Anxiety and Depression Scale (HADS), The Hamilton Rating Scale for Depression, and The Beck Depression Inventory. Safety profile was evaluated using The UKU Side Effect Rating Scale (UKU). The specified psychometric scales reflect the clinical presentation of the depressive disorder: higher scores indicate greater depression. Patients were examined a day after fluvoxamine therapy (day 6 of the inpatient treatment course) and on days 14 and 21 of the inpatient treatment course (days 9 and 16 of fluvoxamine therapy). A higher score difference corresponds to greater changes in clinical presentation and to higher efficacy of treatment.

Statistical analysis of the results was performed with nonparametric methods using the "Statsoft Statistica v. 10.0" (Dell Statistica, Tulsa, OK, USA). The normality of samples distribution was evaluated using W-Shapiro-Wilk test and was taken into account when choosing a method. The differences were considered as statistically significant at $P<0.05$ (power in excess of $80 \%$ ). To compare two independent groups Mann-Whitney $U$-test was used. Research data are presented as median and interquartile range ([Q1; Q3]) or, in the case of normal distribution, as the arithmetic mean and standard deviation (mean \pm standard deviation).

\section{Results}

The CYP2D6 genotyping by polymorphic marker $1846 G>A$ (rs3892097) performed in 45 patients with alcohol use disorder revealed the following:

- The number of patients with no mutant CYP2D6 (genotype $G G)$ was $29(64.4 \%)$;

- The number of patients with heterozygous polymorphism $1846 G>A$ of $C Y P 2 D 6$ gene (genotype $G A$ ) was $17(35.6 \%)$;

- There were no patients with homozygous polymorphism $1846 G>A$ of $C Y P 2 D 6$ gene (genotype $A A$ ).
The distribution of genotypes corresponded to Hardy-Weinberg equilibrium in the European population $\left(\chi^{2}=2.36 ; P=0.12\right)$.

The results of data analysis performed for psychometric scales and the side effect rating scale in patients who received fluvoxamine are presented in Tables 1-3.

Dynamics of changes in the HADS scores across patients with different genotypes are shown in Figure 1. Dynamics of changes in the UKU scores across patients with different genotypes are shown in Figure 2.

We compared the dynamics of changes in the UKU scale scores across patients with different genotypes. The results of our analysis are presented in Tables 4 and 5.

Dynamics of changes in the HADS scores across patients with different genotypes are shown in Figure 3A and B. Dynamics of changes in the UKU scores across patients with different genotypes are shown in Figure 4A and B.

\section{Discussion}

In the study, it was shown that the efficacy and safety profiles of fluvoxamine in patients with affective disorders and

Table I The results of psychometric scales and side effect rating scale data analysis (scores) in patients who received fluvoxamine obtained after visit I (day 5 of the inpatient treatment course)

\begin{tabular}{llll}
\hline Scale & GG & GA & $P$-value \\
\hline SoPA & $22.000[20.000 ; 25.000]$ & $24.000[22.000 ; 26.000]$ & 0.059 \\
PACS & II.000[10.000; 12.000] & $10.000[9.000 ; 11.000]$ & 0.091 \\
VAS & $54.000[47.000 ; 59.000]$ & $56.000[50.000 ; 62.000]$ & 0.418 \\
CGI & $4.000[4.000 ; 5.000]$ & $5.000[4.000 ; 5.000]$ & 0.716 \\
HADS & $36.000[34.000 ; 41.000]$ & $37.000[34.000 ; 39.000]$ & 0.945 \\
HAM-D & $21.000[19.000 ; 25.000]$ & $21.000[19.000 ; 24.000]$ & 0.819 \\
BDI & $55.000[54.000 ; 58.000]$ & $58.000[54.000 ; 60.000]$ & 0.343 \\
UKU & $1.000[1.000 ; 1.000]$ & $1.000[1.000 ; 1.000]$ & 0.184 \\
\hline
\end{tabular}

Note: Data has been presented in as median and interquartile range.

Abbreviations: BDI, Beck Depression Inventory; CGI, Clinical Global Impression; HADS, Hospital Anxiety and Depression Scale; HAM-D, Hamilton Rating Scale for Depression; PACS, Penn Alcohol Craving Scale; SoPA, Scale of Pathological Addiction; UKU, The UKU Side Effect Rating Scale; VAS, Visual Analog Scale.

Table 2 The results of psychometric scales and side effect rating scale data analysis (scores) in patients who received fluvoxamine obtained after visit 2 (day 14 of the inpatient treatment course)

\begin{tabular}{llll}
\hline Scale & GG & GA & $P$-value \\
\hline SoPA & $11.000[10.000 ; 12.000]$ & $19.000[16.000 ; 20.000]$ & 0.000 \\
PACS & $4.000[3.000 ; 5.000]$ & $7.000[7.000 ; 8.000]$ & 0.000 \\
VAS & $35.000[29.000 ; 39.000]$ & $43.000[39.000 ; 46.000]$ & 0.001 \\
CGI & $2.000[2.000 ; 3.000]$ & $4.000[4.000 ; 4.000]$ & 0.000 \\
HADS & $16.000[15.000 ; 20.000]$ & $30.000[29.000 ; 32.000]$ & 0.000 \\
HAM-D & $10.000[10.000 ; 12.000]$ & $15.000[14.000 ; 16.000]$ & 0.000 \\
BDI & $24.000[21.000 ; 25.000]$ & $42.000[39.000 ; 43.000]$ & 0.000 \\
UKU & $6.000[4.000 ; 6.000]$ & $9.000[9.000 ; 10.000]$ & 0.000 \\
\hline
\end{tabular}

Note: Data has been presented in as median and interquartile range.

Abbreviations: BDI, Beck Depression Inventory; CGI, Clinical Global Impression; HADS, Hospital Anxiety and Depression Scale; HAM-D, Hamilton Rating Scale for Depression; PACS, Penn Alcohol Craving Scale; SoPA, Scale of Pathological Addiction; UKU, The UKU Side Effect Rating Scale; VAS, Visual Analog Scale. 
Table 3 The results of psychometric scales and side effect rating scale data analysis (scores) in patients who received fluvoxamine obtained after visit 3 (day $2 \mathrm{I}$ of the inpatient treatment course)

\begin{tabular}{llll}
\hline Scale & GG & GA & $P$-value \\
\hline SoPA & $3.000[2.000 ; 3.000]$ & $5.000[5.000 ; 7.000]$ & 0.000 \\
PACS & $2.000[2.000 ; 2.000]$ & $1.000[1.000 ; 2.000]$ & 0.015 \\
VAS & $13.000[10.000 ; 16.000]$ & $29.000[24.000 ; 32.000]$ & 0.000 \\
CGI & $0.000[0.000 ; 1.000]$ & $2.000[2.000 ; 2.000]$ & 0.000 \\
HADS & $5.000[3.000 ; 6.000]$ & $12.000[11.000 ; 15.000]$ & 0.000 \\
HAM-D & $4.000[2.000 ; 5.000]$ & $6.000[6.000 ; 7.000]$ & 0.000 \\
BDI & $21.000[13.000 ; 28.000]$ & $20.000[18.000 ; 22.000]$ & 0.918 \\
UKU & $5.000[1.000 ; 9.000]$ & $19.000[18.000 ; 22.000]$ & 0.000 \\
\hline
\end{tabular}

Note: Data has been presented in as median and interquartile range.

Abbreviations: BDI, Beck Depression Inventory; CGI, Clinical Global Impression; HADS, Hospital Anxiety and Depression Scale; HAM-D, Hamilton Rating Scale for Depression; PACS, Penn Alcohol Craving Scale; SoPA, Scale of Pathological Addiction; UKU, The UKU Side Effect Rating Scale; VAS, Visual Analog Scale.

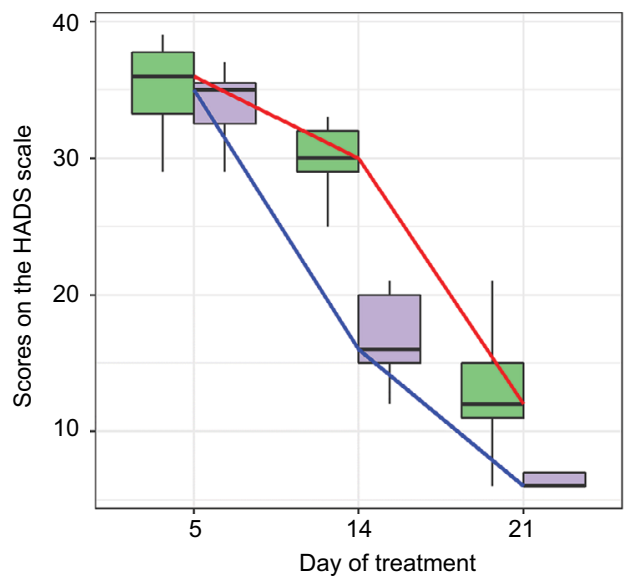

官Genotype GA 官Genotype GG

Figure I Dynamics of changes in HADS scores across patients with different genotypes on days 5, 14, and 21 of the inpatient treatment course (data are presented as Me and IQR).

Abbreviations: HADS, Hospital Anxiety and Depression Scale; IQR, interquartile range; Me, median.

comorbid alcohol use disorder correlated with CYP2D6 genetic polymorphism. The reduced efficacy and worsened safety profile of fluvoxamine therapy were revealed in patients carrying one A allele in $1846 G>A$ ( $r s 3892097$ ). Probably, this correlates with the reduced biotransformation and elimination rates of fluvoxamine and drug cumulation in these patients. This in turn leads to an increased amount of medication reaching the receptor targets of fluvoxamine and to a greater effect on serotonin transport. The acceleration of serotonin transport in the central nervous system neurons results in dose-dependent undesirable side effects (vertigo, headache, indigestion, xerostomia, increased anxiety, etc.) and in reduced efficacy of the depressive disorder therapy, as treatment with any antidepressant given in doses exceeding

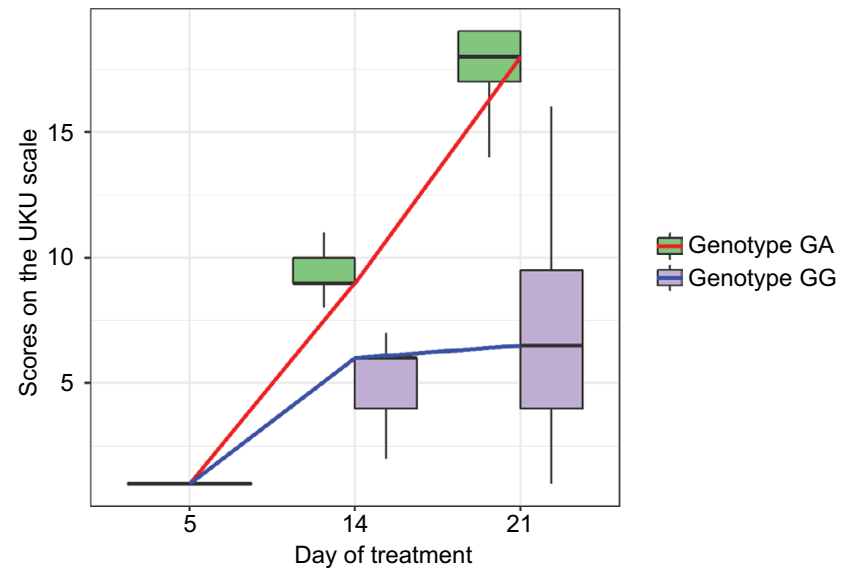

Figure 2 Dynamics of changes in the UKU scale scores across patients with different genotypes on days 5,14 , and 21 of the inpatient treatment course (data are presented as Me and IQR).

Abbreviations: IQR, interquartile rage; Me, median; UKU, The UKU Side Effect Rating Scale.

Table 4 Dynamics of changes in psychometric scales and side effect rating scale scores on days 5 to 14 of the inpatient treatment course in patients with different genotypes of CYP2D6 gene by polymorphic marker $1846 \mathrm{G}>\mathrm{A}$

\begin{tabular}{llll}
\hline Scale & GG & GA & $P$-value \\
\hline SoPA & $12.000[10.000 ; 13.000]$ & $6.000[3.000 ; 9.000]$ & 0.000 \\
PACS & $7.000[6.000 ; 8.000]$ & $3.000[2.000 ; 4.000]$ & 0.000 \\
VAS & $18.000[13.000 ; 27.000]$ & $17.000[6.000 ; 22.000]$ & 0.202 \\
CGI & $2.000[1.000 ; 3.000]$ & $1.000[0.000 ; 1.000]$ & 0.000 \\
HADS & $17.000[15.000 ; 24.000]$ & $7.000[4.000 ; 11.000]$ & 0.000 \\
HAM-D & $11.000[10.000 ; 13.000]$ & $6.000[5.000 ; 9.000]$ & 0.003 \\
BDI & $32.000[28.000 ; 39.000]$ & $16.000[13.000 ; 19.000]$ & 0.000 \\
UKU & $5.000[3.000 ; 5.000]$ & $8.000[8.000 ; 9.000]$ & 0.000 \\
\hline
\end{tabular}

Note: Data has been presented in as median and interquartile range.

Abbreviations: BDI, Beck Depression Inventory; CGI, Clinical Global Impression; HADS, Hospital Anxiety and Depression Scale; HAM-D, Hamilton Rating Scale for Depression; PACS, Penn Alcohol Craving Scale; SoPA, Scale of Pathological Addiction; UKU, The UKU Side Effect Rating Scale; VAS, Visual Analog Scale.

Table 5 Dynamics of changes in psychometric scales and side effect rating scale scores on days 14 to 21 of the inpatient treatment course in patients with different genotypes of CYP2D6 gene by polymorphic marker $1846 \mathrm{G}>\mathrm{A}$

\begin{tabular}{llll}
\hline Scale & GG & GA & $P$-value \\
\hline SoPA & $5.000[5.000 ; 6.500]$ & $13.000[8.000 ; 15.000]$ & 0.000 \\
PACS & $3.000[3.000 ; 4.000]$ & $2.000[1.250 ; 3.000]$ & 0.000 \\
VAS & $16.000[14.500 ; 21.500]$ & $30.500[25.250 ; 36.500]$ & 0.000 \\
CGI & $2.000[1.000 ; 2.000]$ & $4.000[3.000 ; 5.000]$ & 0.000 \\
HADS & $9.000[7.500 ; 13.000]$ & $13.500[9.500 ; 16.000]$ & 0.000 \\
HAM-D & $8.000[5.500 ; 9.500]$ & $11.000[9.250 ; 13.000]$ & 0.000 \\
BDI & $11.000[8.000 ; 16.000]$ & $32.000[29.250 ; 34.750]$ & 0.000 \\
UKU & $5.000[3.000 ; 5.500]$ & $10.000[6.250 ; 12.000]$ & 0.000 \\
\hline
\end{tabular}

Note: Data has been presented in as median and interquartile range. Abbreviations: BDI, Beck Depression Inventory; CGI, Clinical Global Impression; HADS, Hospital Anxiety and Depression Scale; HAM-D, Hamilton Rating Scale for Depression; PACS, Penn Alcohol Craving Scale; SoPA, Scale of Pathological Addiction; UKU, The UKU Side Effect Rating Scale; VAS, Visual Analog Scale. 
A

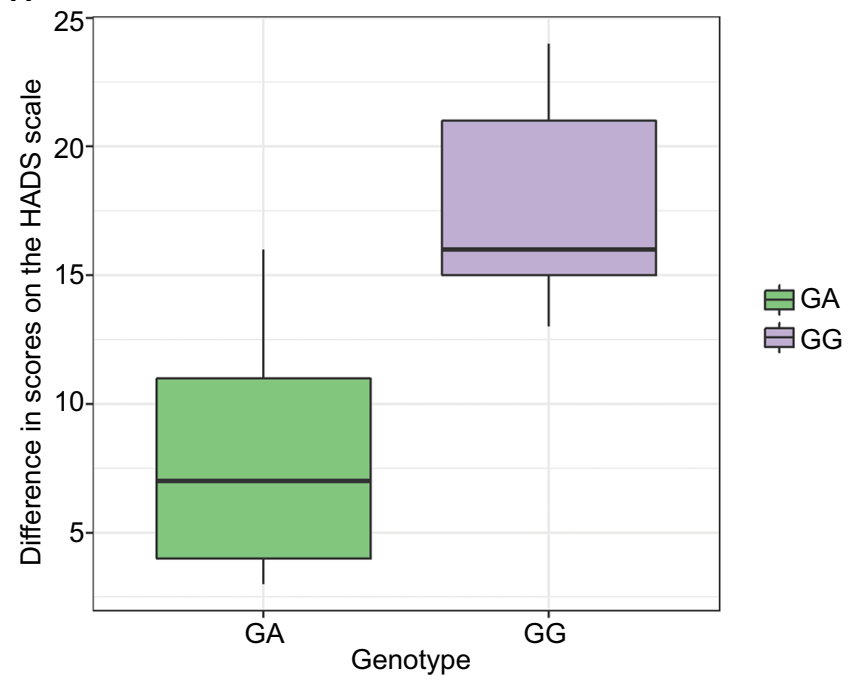

B

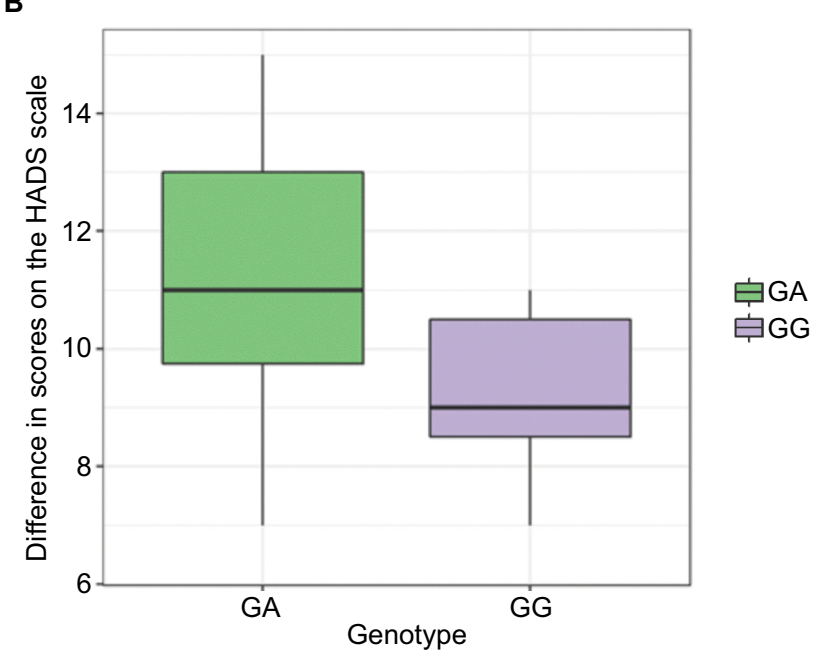

Figure 3 (A) HADS scores across patients with different genotypes of CYP2D6 gene by polymorphic marker 1846G>A on days 5 to 14 of the inpatient treatment course (data are presented as Me and IQR). (B) Dynamics of changes in HADS scores across patients with different genotypes of CYP2D6 gene by polymorphic marker 1846G>A on days 14 to $2 \mathrm{I}$ of the inpatient treatment course (data are presented as Me and IQR).

Abbreviations: HADS, Hospital Anxiety and Depression Scale; IQR, interquartile range; Me, median.

the intended ones and within the toxic concentration range reduces the antidepressive effect of the medication.

The results of our study are in agreement with the results of several previously conducted studies, ${ }^{7,23}$ but at the same time are opposite to the results obtained in one study. ${ }^{15}$ The most likely reason may be that Ohara et $\mathrm{al}^{15}$ evaluated the effect of CYP2D6*10 genetic polymorphism on fluvoxamine equilibrium plasma concentration level, while $C Y P 2 D 6^{* 4}$ genetic polymorphism evaluated in our study probably has a greater effect on CYP2D6 activity than CYP2D6*10. Furthermore, the study population was highly heterogeneous in terms of allelic frequencies, leaving the researchers unable to achieve the required statistical power.
Results of our study should be taken into consideration when prescribing fluvoxamine to patients with depressive disorders and comorbid alcohol use disorder since it will allow increasing the efficacy of fluvoxamine therapy and decreasing the risk of undesirable side effects. However, according to the last edition of recommendations by the Clinical Pharmacogenetics Implementation Consortium, ${ }^{8}$ fluvoxamine dose should be initialized with the recommended starting dose in patients with intermediate metabolism (ie, $G A$ genotype of polymorphic marker $C Y P 2 D 6$ $(1846 G>A))$, whereas in patients carrying homozygous mutant allele (ie, $A A$ genotype) it is recommended to replace fluvoxamine with another antidepressant whose 
A

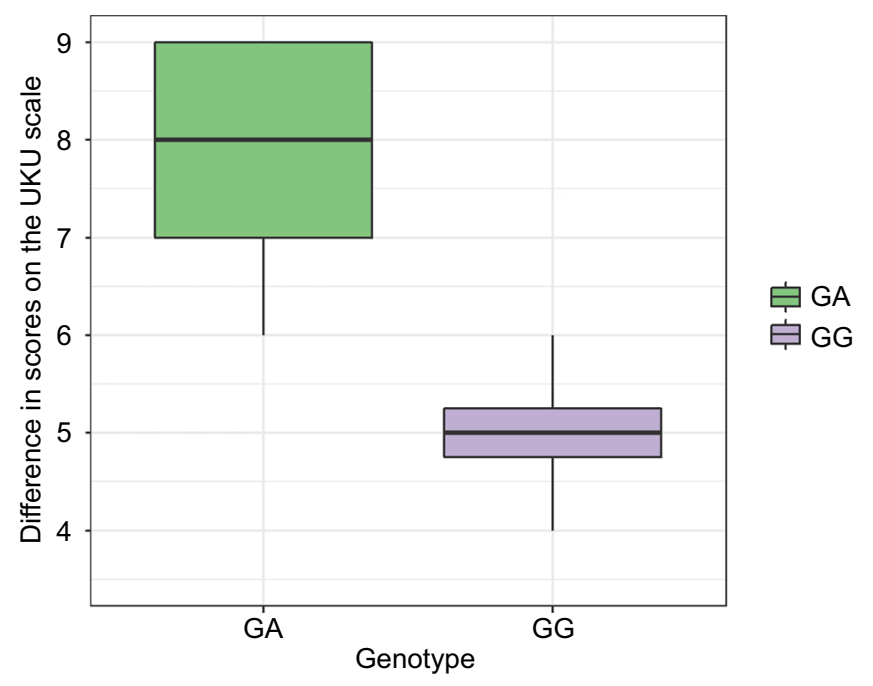

B

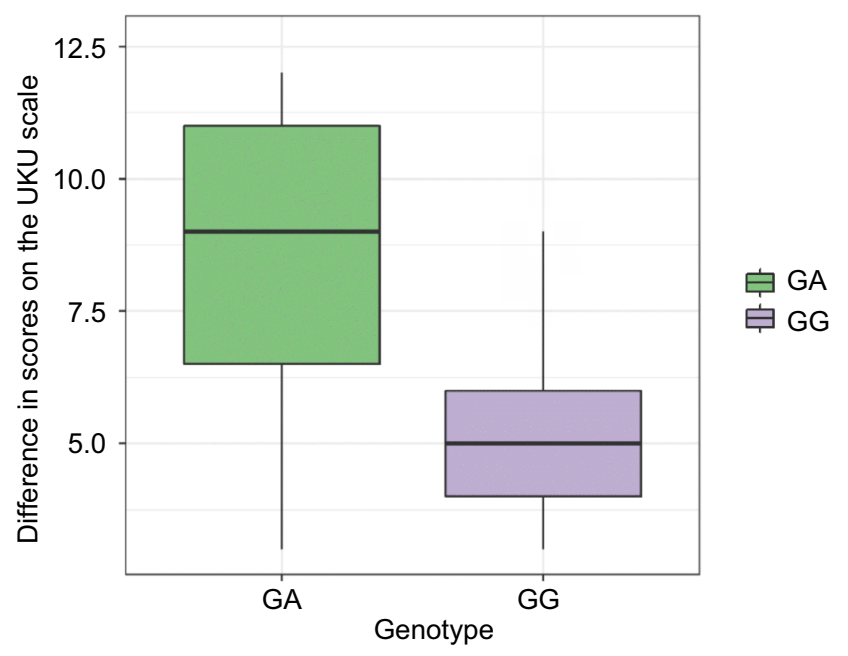

Figure 4 (A) Dynamics of changes in the UKU scale scores across patients with different genotypes of CYP2D6 gene by polymorphic marker 1846G>A on days 5 to 14 of the inpatient treatment course (data are presented as Me and IQR). (B) Dynamics of changes in the UKU scale scores across patients with different genotypes of CYP2D6 gene by polymorphic marker I846G>A on days I4 to $2 \mathrm{I}$ of the inpatient treatment course (data are presented as Me and IQR).

Abbreviations: IQR, interquartile rage; Me, median; UKU, The UKU Side Effect Rating Scale.

biotransformation is not affected by $C Y P 2 D 6$ or, in case of impossibility, to reduce the initial fluvoxamine dose by $25 \%-50 \%$.

\section{Conclusion}

The study conducted in 45 patients with depressive disorders and comorbid alcohol use disorder revealed that $C Y P 2 D 6$ genetic polymorphism could worsen the efficacy and safety profile of fluvoxamine. This should be considered when prescribing fluvoxamine to such patients to reduce the risk of undesirable side effects and pharmacoresistance.

\section{Acknowledgment}

This work was supported by the project titled "Fundamental research and exploratory research in priority areas of research" (No. 16-15-00227) of the Russian Science Foundation.

\section{Disclosure}

The authors report no conflicts of interest in this work.

\section{References}

1. Bertilsson L, Dahl ML, Dalén P, Al-Shurbaji A. Molecular genetics of CYP2D6: clinical relevance with focus on psychotropic drugs. $\mathrm{Br} \mathrm{J}$ Clin Pharmacol. 2002;53(2):111-122. 
2. Boschloo L, Vogelzangs N, Smit JH, et al. Comorbidity and risk indicators for alcohol use disorders among persons with anxiety and/or depressive disorders: findings from the Netherlands Study of Depression and Anxiety (NESDA). J Affect Disord. 2011;131(1-3):233-242.

3. Charlier C, Broly F, Lhermitte M, Pinto E, Ansseau M, Plomteux G. Polymorphisms in the CYP 2D6 gene: association with plasma concentrations of fluoxetine and paroxetine. Ther Drug Monit. 2003;25(6):738-742.

4. Dalén P, Dahl ML, Roh HK, et al. Disposition of debrisoquine and nortriptyline in Korean subjects in relation to CYP2D6 genotypes, and comparison with Caucasians. Br J Clin Pharmacol. 2003;55(6):630-634.

5. Eap CB, Bondolfi G, Zullino D, et al. Concentrations of the enantiomers of fluoxetine and norfluoxetine after multiple doses of fluoxetine in cytochrome P4502D6 poor and extensive metabolizers. J Clin Psychopharmacol. 2001;21(3):330-334.

6. Fukuda T, Nishida Y, Zhou Q, Yamamoto I, Kondo S, Azuma J. The impact of the CYP2D6 and CYP2C19 genotypes on venlafaxine pharmacokinetics in a Japanese population. Eur J Clin Pharmacol. 2000;56(2):175-180.

7. Gerstenberg G, Aoshima T, Fukasawa T, et al. Effects of the CYP 2D6 genotype and cigarette smoking on the steady-state plasma concentrations of fluvoxamine and its major metabolite fluvoxamino acid in Japanese depressed patients. Ther Drug Monit. 2003;25(4):463-468.

8. Hicks JK, Bishop JR, Sangkuhl K, et al. Clinical harmacogenetics Implementation Consortium (CPIC) Guideline for CYP2D6 and CYP2C19 genotypes and dosing of selective serotonin reuptake inhibitors. Clin Pharmacol Ther. 2015;98(2):127-134.

9. Hiemke C, Baumann P, Bergemann N, et al. AGNP Consensus guidelines for therapeutic drug monitoring in psychiatry: update 2011. Pharmacopsychiatry. 2011;44(6):195-235.

10. Ivanec NN. Drug Addiction: National Leadership. Moscow: GEOTAR Media; 2008:496.

11. Lee SY, Sohn KM, Ryu JY, Yoon YR, Shin JG, Kim JW. Sequencebased CYP2D6 genotyping in the Korean population. Ther Drug Monit. 2006;28(3):382-387.

12. Lin JH, Lu AY. Inhibition and induction of cytochrome P450 and the clinical implications. Clin Pharmacokinet. 1998;35(5):361-390.

13. McAlpine DE, Biernacka JM, Mrazek DA, et al. Effect of cytochrome P450 enzyme polymorphisms on pharmacokinetics of venlafaxine. Ther Drug Monit. 2011;33(1):14-20.
14. Nichols AI, Lobello K, Guico-Pabia CJ, Paul J, Preskorn SH. Venlafaxine metabolism as a marker of cytochrome P450 enzyme 2D6 metabolizer status. J Clin Psychopharmacol. 2009;29(4):383-386.

15. Ohara K, Tanabu S, Ishibashi K, Ikemoto K, Yoshida K, Shibuya H. CYP2D6*10 alleles do not determine plasma fluvoxamine concentration/dose ratio in Japanese subjects. Eur J Clin Pharmacol. 2003;58(10):659-661.

16. U.S. Department of Health and Human Services, Substance Abuse and Mental Health Services Administration Center for Behavioral Health Statistics and Quality. Results from the 2010 National Survey on Drug Use and Health: Summary of National Findings. Available from: http://www.samhsa.gov/data/NSDUH/2k10NSDUH/2k10Results.htm. Accessed May 18, 2018.

17. Sawamura K, Suzuki Y, Someya T. Effects of dosage and CYP2D6mutated allele on plasma concentration of paroxetine. Eur J Clin Pharmacol. 2004;60(8):553-557.

18. Shen H, He MM, Liu H, et al. Comparative metabolic capabilities and inhibitory profiles of CYP2D6.1, CYP2D6.10, and CYP2D6.17. Drug Metab Dispos. 2007;35(8):1292-1300.

19. Stingl JC, Brockmoller J, Viviani R. Genetic variability of drug-metabolizing enzymes: the dual impact on psychiatric therapy and regulation of brain function. Mol Psychiatry. 2013;18:273-287.

20. Teeson M, Hall W, Lynskey M, Degenhardt L. Alcohol and druguse disorders in Australia: implications of the National Survey of Mental Health and Wellbeing. Aust N Z J Psychiatry. 2000;34(2): 206-213.

21. Ueda M, Hirokane G, Morita S, et al. The impact of CYP2D6 genotypes on the plasma concentration of paroxetine in Japa-nese psychiatric patients. Prog Neuropsychopharmacol Biol Psychiatry. 2006;30(3):486-491.

22. Wang Z, Wang S, Huang M, Hu H, Yu L, Zeng S. Characterizing the effect of cytochrome P450 (CYP) 2C8, CYP2C9, and CYP2D6 genetic polymorphisms on stereoselective $\mathrm{N}$-demethylation of fluoxetine. Chirality. 2014;26(3):166-173.

23. Watanabe J, Suzuki Y, Fukui N, et al. Dose-dependent effect of the CYP2D6 genotype on the steady-state fluvoxamine concentration. Ther Drug Monit. 2008;30:705-708.

24. Zarkin GA, Bray JW, Aldridge A, et al. The effect of alcohol treatment on social costs of alcohol dependence: results from the COMBINE study. Med Care. 2010;48(5):396-401.
Pharmacogenomics and Personalized Medicine

\section{Publish your work in this journal}

Pharmacogenomics and Personalized Medicine is an international, peerreviewed, open access journal characterizing the influence of genotype on pharmacology leading to the development of personalized treatment programs and individualized drug selection for improved safety, efficacy and sustainability. This journal is indexed on the American Chemical
Dovepress

Society's Chemical Abstracts Service (CAS). The manuscript management system is completely online and includes a very quick and fair peer-review system, which is all easy to use. Visit http://www.dovepress. com/testimonials.php to read real quotes from published authors. 